\title{
Dystrophin analysis using a panel of anti-dystrophin antibodies in Duchenne and Becker muscular dystrophy
}

Institute of Child

Neurology and

Psychiatry, Cagliari,

Italy

F Muntoni

A Mateddu

C Cianchetti

M Marrosu

Jerry Lewis Muscle

Centre, Hammersmith Hospital, London, UK A Clerk

Institute of Clinic and Biology of Growing

Age, Cagliari, Italy

$M$ Cau

$\mathrm{R}$ Congiu

A Cao

M A Melis

Correspondence to: Dr Muntoni, Istituto di Neuropsichiatria Infantile, Via Ospedale 119, 09124 Cagliari, Italy.

Received 31 July 1991 and in revised form 29 October 1991.

Accepted 9 January 1992
Francesco Muntoni, Anna Mateddu, Carlo Cianchetti, Maria Giovanna Marrosu, Angela Clerk, Milena Cau, Rita Congiu, Antonio Cao, Maria Antonietta Melis
The underlying biochemical defects responsible for Duchenne and Becker muscular dystrophy are abnormalities of dystrophin, the protein product of the Duchenne muscular dystrophy (DMD) gene. ${ }^{12}$ Immunocytochemical studies have shown that in normal muscle, dystrophin is visualised as a continuous ring of staining at the periphery of every muscle fibre $;^{34}$ in DMD muscle the staining in most cases is totally absent, ${ }^{5}$ although the occurrence of scattered positive fibres has been reported. $^{68}$ In the majority of patients with BMD a patchy or discontinuous staining pattern around most fibres has been described, the staining intensity being usually fainter than that seen in normal muscle; ${ }^{59}$ furthermore a variability in staining between individual fibres has been recorded, ${ }^{6}$ although no abnormalities were detected in several patients with mild BMD. ${ }^{8}$ In most of these studies only one $\mathrm{N}$-terminal antibody was used.

In this study we evaluated a group of 19 patients with Xp21 muscular dystrophy, displaying a continuous spectrum of severity ranging from severe DMD to asymptomatic patients. We correlated the pattern of dystrophin immunofluorescence abnormalities, studied with antibodies directed towards seven different regions of dystrophin CDNA, with clinical severity as well as type and extension of gene deletions, when found. Our results suggest that the combined use of several antidystrophin antibodies is more informative than the use of one or a small number of antibodies for the prognostic diagnosis of $\mathrm{Xp} 21$ disorders.

\section{Materials and methods}

Each biopsy sample was tested with 7 different anti-dystrophin antibodies, two of which were monoclonal antisera (Dys 1 and Dys 2, Novocastra Laboratories, UK). The polyclonal antibodies $90 \mathrm{~K}(1), \mathrm{H} 12$ and $\mathrm{P} 6$ were the generous gift of P Strong and T Sherratt, London, while antibody $\mathrm{P} 20$ and D1-2 were donated by $\mathrm{I}$ Ginjaar, Leiden (The Netherlands) and $A$ Mora and F Cornelio, Milan (Italy), respectively. The mouse peptides correspond to amino acids 53-664 (D1-2), 407-815 (90K), 1181-1388 (Dys I), 1750-2248 (P2), 2542-3025 (H12), 2814-3028(P6), 3688-3685 (Dys II). In fig 1 the region of the protein recognised by each antibody is indi-

Figure 1 The four domains of dystrophin with the region of the protein recognised by each of the seven antibodies used is reported. 
cated. Monoclonal antibodies against human $\beta$ spectrin (56A) were a gift of Carol Lovegrove, London. Fluorescinated or biotinylated secondary antibodies and Texas Red were purchased from Chemicon.

All patients in this study attended the muscular dystrophy clinic at the Child Neurology and Psychiatry Institute, Cagliari. The age at which patients became wheelchair bound was the main clinical parameter used to differentiate DMD, intermediate and BMD phenotypes. Patients who became permanently wheelchair bound before the age of 13 were classified as DMD, whereas individuals who were amubulatory at the age of 16 years were classified as BMD patients; if only minor difficulties were present after the age of 30 years we diagnosed mild BMD. Subjects who became wheelchair bound between the ages of 13 and 16 years were classified as intermediate. Those patients who were too young to be differentially classified according to the above scheme were assessed using clinical, histopathological, genetic and biochemical data.

All patient muscle samples were obtained with needle muscle biopsy of the quadriceps. Samples were immediately frozen in liquid nitrogen-cooled isopentane and stored in liquid nitrogen. Previously sectioned slices were stored at $-30^{\circ} \mathrm{C}$ until use. A total of 19 patients (8 DMD, age range 19 months-13 years and one $\mathrm{DMD}$ foetus, $8 \mathrm{BMD}$, age range 7-57 years; 3 patients with an intermediate phenotype between DMD and BMD, age range 9-12 years) were studied. Immunocytochemical analysis was performed on $6 \mu$ thick unfixed frozen tissue sections. Normal muscle samples were processed in parallel with biopsies from patients to provide a positive control of immunolabelling. Muscle histology and histochemistry were studied according to the method described by Dubowitz. ${ }^{10}$ Twenty five patients with non-Xp21 muscular dystrophies (6 autosomal recessive, 4 autosomal dominant, 7 facio-scapulohumeral, 1 Fukujama, 2 Emery-Dreifuss, 5 congenital muscular dys- trophy) were also studied. Western Blot analysis was performed as previously described ${ }^{15}$ on all patients with BMD in whom no deletion was found to confirm the diagnosis.

Screening for deletions was performed by direct amplification of exons by multiplex $P_{C R}{ }^{112}$ and by Southern blotting with CDNA probes on Hind III digest. ${ }^{13}$

\section{Results}

Pattern of dystrophin abnormalities in BMD patients

Various abnormalities were detected in the muscle of patients with BMD (table 1), the most frequent being an immunostaining variability between individual fibres. In contrast to what is consistently found in normal muscle (that is, identical levels of immunostaining in all fibres, fig 2), the interfibre variability in staining, using any antibody, was the most frequent abnormality encountered in the vast majority of BMD patients (table 1, fig 3). A discordance in staining between the various antibodies was the second most frequent abnormality. This was also noted in patients with very mild or preclinical phenotypes, in which the use of just one or two antidystrophin antibodies gave normal results when taken individually. Only the comparison of results obtained with antibodies raised against different portions of the protein was revealing in these mildly affected individuals. Several patients had deletions of the CDNA in a region partially encompassed by one of the antibodies used (for example BMD 2 for $\mathrm{H} 12$ antibody) which gave a very faint signal in this subset of cases. A discontinuous labelling of the membrane was the third most common abnormality, but was confined to patients in the moderate/severe range of BMD (fig 4); rare dystrophin negative fibres were detected in these subjects (table 1). No specific immunofluorescence abnormality was detected in the 25 patients with non-Xp21 dystrophies except

Table 1 Dystrophin abnormalities on tissue sections in BMD and intermediate patients

\begin{tabular}{|c|c|c|c|c|c|}
\hline Patient & Age (years) & Phenotype & Exon deleted & Reading-frame & Pattern of fibre labelling \\
\hline BMD 1 & 27 & Moderate & $48-50$ & - & \multirow{11}{*}{$\begin{array}{l}80 \% \text { continuous, of variable intensity; } 10 \% \\
\text { discontinuous, moderate intensity. } \\
100 \% \text { normal for all antibodies except for } \mathrm{H} 12 \text { (most } \\
\text { fibres showed variable intensity with this antibody. } \\
90 \% \text { continuous, of variable intensity; } 8 \% \\
\left.\text { discontinuous, faint; } 28 \text { of negative fibres. ( }{ }^{\star}\right) \\
75 \% \text { continuous, of variable intensity; } 23 \% \\
\text { discontinuous, of moderate or faint intensity; } 2 \% \text { of } \\
\text { negative fibres. ( } \star \text { ) } \\
5 \% \text { continuous, variable intensity; } 70 \% \\
\text { discontinuous, faint or very faint; } 25 \% \text { of negative } \\
\text { fibres. } \\
94 \% \text { continuous, variable intensity; } 6 \% \\
\text { discontinuous, moderate intensity. ( }{ }^{\star} \text { ) } \\
100 \% \text { discontinuous, faint or very faint. No } \\
\text { immunoreactivity was detected with } \mathrm{D} 1-2 \text { antibody. } \\
70 \% \text { continuous, normal or variable intensity; } 30 \% \\
\text { discontinuous, faint or very faint. ( } \star \text { ) } \\
100 \% \text { discontinous, faint or very faint. } 99 \% \text { of fibres } \\
\text { showed no immunoreactivity with } \mathrm{D} 1-2 \text { antibody. } \\
98 \% \text { discontinuous, moderate intensity; } 2 \% \text { of } \\
\text { negative fibres. } \\
88 \% \text { continuous, variable intensity; } 8 \% \\
\text { discontinuous, moderate; } 4 \% \text { negative fibres. }\end{array}$} \\
\hline BMD 2 & 8 & Preclinical & $48-51$ & + & \\
\hline BMD 17 & 10 & Preclinical & non deletion & & \\
\hline BMD 19 & 12 & Mild & $48-51$ & + & \\
\hline B/DMD 35 & 12 & Intermediate & Non-deletion & & \\
\hline BMD 51 & 9 & Mild & $49-51$ & + & \\
\hline B/DMD 63 & 9 & Intermediate & 3-7 & - & \\
\hline BMD 73 & 57 & Mild & non deletion & & \\
\hline B/DMD 87 & 11 & Intermediate & $3-9$ & + & \\
\hline BMD 89 & 25 & Mild & non deletion & & \\
\hline BMD 92 & 7 & Preclinical & non deletion & & \\
\hline
\end{tabular}

The symbol + or - under the heading READING-FRAME indicates the maintenance of reading frame. The asterisk $\left(^{\star}\right)$ indicates that reduction in immunostaining was detected using C-terminal antibodies or antibodies distal to a
deleted portion of the protein. 


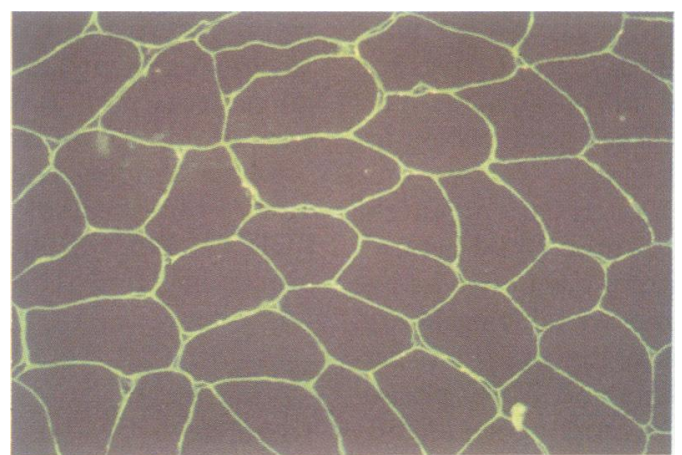

Figure 2 Normal muscle stained with P6 antibodies (320x). All fibres are equally stained by anti dystrophin antibody.

for the absence of dystrophin in fibres in an advanced state of necrosis. The same fibres lacked surface immunolabelling with $\beta$ spectrin, indicating a complete loss of their plasma membrane. Western blot analysis performed with $90 \mathrm{~K}$ and P6 antibodies on all our patients with BMD confirmed the dystrophin abnormalities detected with immunofluorescence (data not shown).

In vitro evidence of abnormal dystrophin breakdown in BMD muscle

When the muscle samples of patients with BMD (when stored at $-30^{\circ} \mathrm{C}$ ) were retested for dystrophin immunoreactivity, a progressive fading of signal intensity was detected after two to 12 months. The degree of immunoreactivity loss was maximal when using antibodies partially encompassed by or distal to a deletion; some variation was also noted using C-terminal antibodies. The same phenomenon (that is, greater loss of immunoreactivity using C-terminal as opposed to $\mathrm{N}$-terminal antibodies) was also noted in patients with BMD in whom no deletion was found. The decrease in immunoreactivity was maximal when the muscle was stored already sectioned; control muscle, or muscle belonging to a patient with non-Xp21 muscle disorders, stored identically, showed no evidence of loss of signal after the same time lapse or even longer (up to a maximum of 2.5 years). No decrease in immunoreactivity with time was noted in serial sections using antibodies to $\beta$-spectrin.

Pattern of dystrophin abnormalities in DMD patients

The greater number of boys with DMD had no

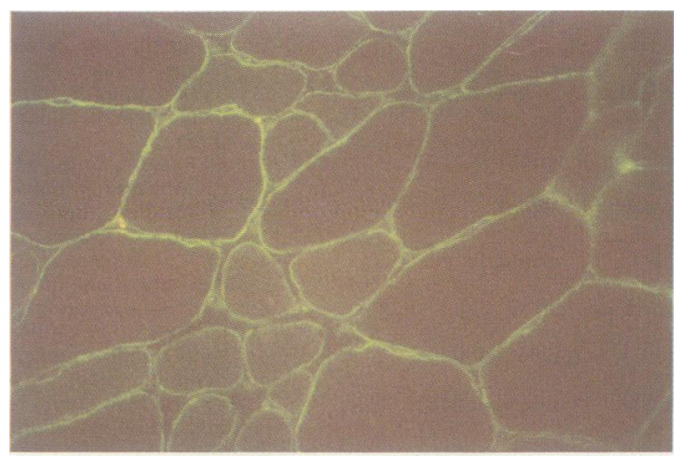

Figure 3 BMD muscle, stained with P6 antibodies $(320 x)$. Not all fibres have identical levels of staining.

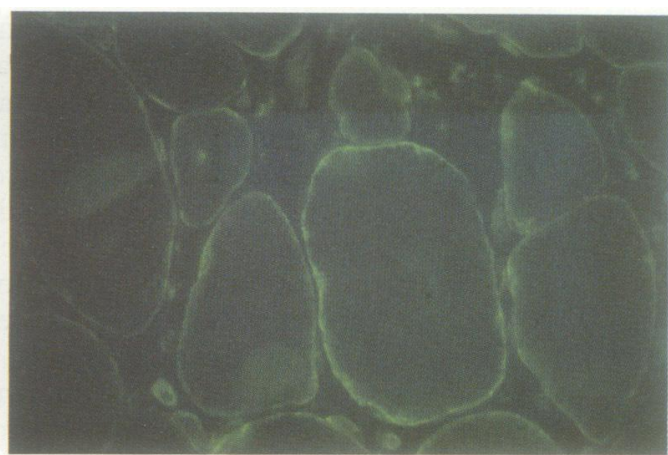

Figure 4 Severe BMD, H12 antibody (320x). Discontinuous and weak labelling is visible in all fibres.

detectable dystrophin with most of the antibodies used (table 2 ). In a few patients (3/10) a very faint immunoreactivity, correctly located at the periphery of the muscle fibres, was detected in the majority of fibres using D1-2 and 90K N-terminal antibodies, but not with all remaining antibodies. The same phenomenon was observed in the muscle of a DMD foetus. A progressive loss of this weak immunoreactivity was also observed in this subgroup of patients with DMD when retested after 3 weeks and up to a couple of months.

When muscle of boys with DMD was analysed using the complete panel of antidystrophin antibodies, the following exceptions to the rule "dystrophin absence = DMD" were detected:

a) Scattered positive fibres in DMD. Occurrence of scattered muscle fibres showing normal immunoreactive sarcolemmal dystrophin was noted in most of the boys with DMD (table 2 and fig 5). The occurrence of these positive fibres was detected with all antibodies used. Immunoreactivity could often be followed, using several serial sections, for more than $120 \mu$ (that is, more than 20 slices) in the majority of cases; sometimes positivity was followed for more than $200 \mu$ before the positive signal was lost. The same phenomenon was found in a DMD foetus (14 weeks), in which the presence of rare positive myotubes (as opposed to negative myotubes) was detected. b) Dystrophin immunoreactivity in the muscle spindle of a boy with DMD. The intrafusal fibres of a muscle spindle of a boy with DMD (patient 41 ) were very brightly stained with all

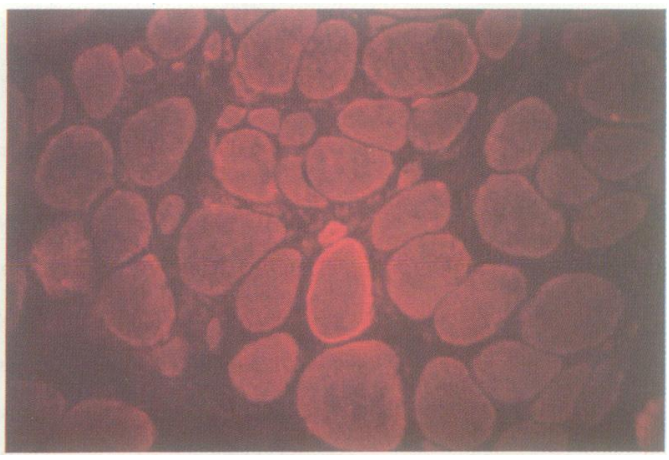

Figure 5. DMD muscle. Only 2 fibres show some dystrophin immunoreactivity (D1-2 antibody, 320x). Extremely weak labelling is visible in some other fibre using this $N$-terminal antibody. 
Table 2 Dystrophin abnormalities on tissue sections in DMD patients

\begin{tabular}{|c|c|c|c|c|}
\hline Patient & Age (years) & Exon deleted & Reading-frame & Pattern of fibre labelling \\
\hline $\begin{array}{l}\text { DMD } 8 \\
\text { DMD } 9 \\
\text { DMD } 41\end{array}$ & $\begin{array}{l}4 \\
9 \\
6\end{array}$ & $\begin{array}{l}35-44 \\
44 \\
\text { non deletion }\end{array}$ & $\overline{-}$ & $\begin{array}{l}1 \% \text { continuous, variable intensity; } 99 \% \text { negative fibres. } \\
2 \% \text { continuous, variable intensity; } 98 \% \text { negative fibres. } \\
0.5 \% \text { continuous, normal intensity (muscle spindle); } 6 \% \\
\text { discontinuous, very faint }(\$) ; 93.5 \% \text { negative fibres. }\end{array}$ \\
\hline $\begin{array}{l}\text { DMD } 49 \\
\text { DMD } 60 \\
\text { DMD } 62\end{array}$ & $\begin{array}{r}11 \\
7 \\
13\end{array}$ & $\begin{array}{l}\text { non deletion } \\
\text { non deletion } \\
45-47\end{array}$ & - & $\begin{array}{l}2 \% \text { discontinuous, very faint }(\$) ; 98 \% \text { negative fibres. } \\
2 \% \text { discontinuous, very faint }(\$) ; 98 \% \text { negative fibres. } \\
4 \% \text { continuous, normal intensity; } 4 \% \text { discontinuous, moderate (\$); } \\
92 \% \text { negative fibres. }\end{array}$ \\
\hline $\begin{array}{l}\text { DMD } 84 \\
\text { FOETUS }\end{array}$ & $\begin{array}{l}7 \\
14 \text { weeks }\end{array}$ & $\begin{array}{l}\text { non deletion } \\
48-58\end{array}$ & - & $\begin{array}{l}1 \% \text { discontinuous, very faint }(\S) ; 99 \% \text { negative fibres. } \\
16 \% \text { continuous, variable intensity }(\S), 1 \% \text { normal intensity; } 4 \% \\
\text { discontinuous, moderate }(\$) ; 79 \% \text { negative myotubes. }\end{array}$ \\
\hline
\end{tabular}

The symbol + or - under the heading READING-FRAME indicates the maintenance of reading frame.

The symbol $(\S)$ indicates tha. some labelling was detectable only with N-terminal antibodies.

antibodies used. In figure 6 immunoreactivity obtained with $90 \mathrm{~K}$ antibody is shown: perinuclear staining was detected only with this antibody. The strong positive immunoreactivity was followed, in serial sections, for approximately $140 \mu$ (20 slices), but disappeared thereafter in all fibres.

c) Split fibres. In DMD, the newly synthesised membrane of a splitting fibre frequently displayed low levels of dystrophin immunoreactivity although the periphery of muscle fibres was negative (fig 7). This positivity was detected with all antibodies. Splits (and vacuoles) were always strongly positive in BMD and non-Xp21 disorders.

Very weak immunostaining was detected in the three patients with an intermediate phenotype. Patient 86 (deleted for exons 3-9) and 63 (exons 3-7 deleted) showed no immunoreactivity with the most $\mathrm{N}$-terminal antibody D1-2, raised against an epitope partially deleted in these two patients (fig 8a), but starting from antibody $90 \mathrm{~K}$ and as far as the most C-terminal antibody a clear, although very weak immunoreactivity was detected (fig $8 \mathrm{~b}$ ); several dystrophin-negative fibres were also present (table 1). Patient 35, who had no deletion of the cDNA showed very weak immunostaining with all antibodies.

Fifty per cent of patients with DMD and BMD exhibited a deletion. In tables 1 and 2 the number of exons deleted is recorded. The deletion altered the reading frame in all patients with DMD but in none of the BMD patients we analysed with the exception of patient 1 , a 27 years old ambulant patient with

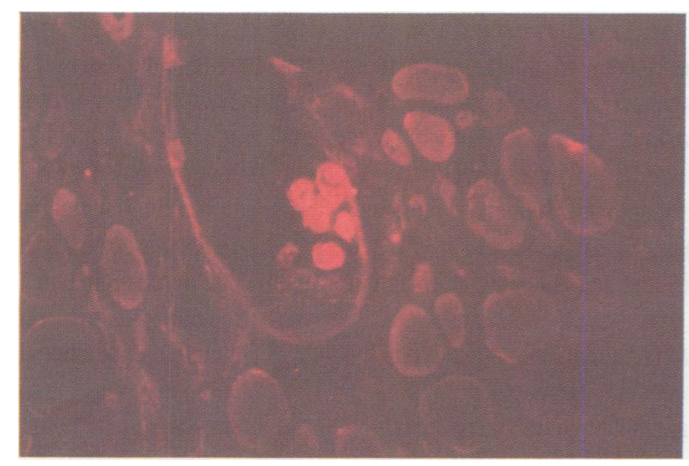

Figure 6 DMD muscle, 90K antibodies (320x). All intrafusal muscle fibres show a distinct immunoreactivity for the antibody, while extrafusal fibres are completely negative. The nuclear membrane of intrafusal fibres is also stained with this antibody.
Becker muscular dystrophy: he was missing exons 48-50, causing a frame-shifting. Of the two subjects with an intermediate phenotype with a deletion, one had an in-frame deletion (subject 87, exons deleted 3-9), while the other carried an out-of-frame deletion (case 63, exons deleted 3-7) (table 2).

\section{Discussion}

Dystrophin deficiency has been well documented as the underlying cause of Duchenne muscular dystrophy by both immunofluorescence and immunoblot analysis. ${ }^{3-914}$ Abnormalities in the quantity and/or quality of dystrophin have also been well characterised in patients with BMD. ${ }^{368}$ In the main part of the original studies only one ( $\mathrm{N}$ - terminal) antibody was used. In this study we have selected a panel of 7 different anti dystrophin antibodies and immunofluorescence analysis in a group of 19 patients with Xp21 disorders.

In patients with $\mathrm{BMD}$ we were able to identify different kinds of abnormalities related to phenotype severity. We established that the most frequent abnormalities in our BMD patients were staining variability between individual fibres (using one antibody) and differences in staining intensity when several antibodies were employed. The use of a complete set of antibodies enabled us to identify very subtle anomalies that cannot be detected with the use of only one antibody in the BMD patients (our data and ${ }^{8}$ ).

A further useful test to reveal abnormalities in patients with very mild BMD was that of restaining serial sections of muscle after storing

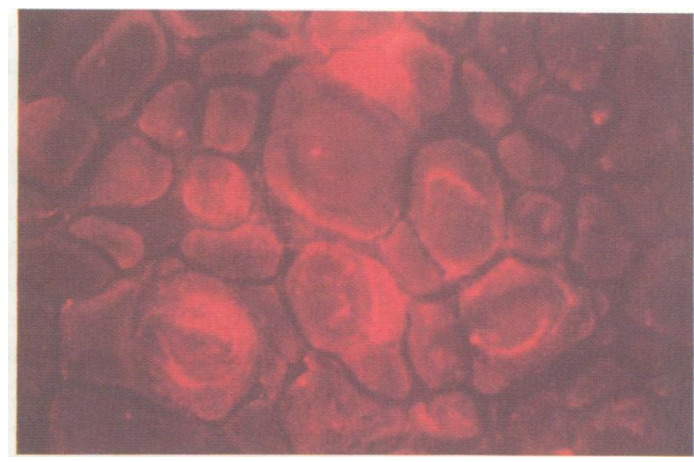

Figure 7 DMD muscle, DYS I antibody (320x). Membrane of several splitting fibres is weakly stained. A necrotic fibres shows some non specific cytoplasmic staining. 


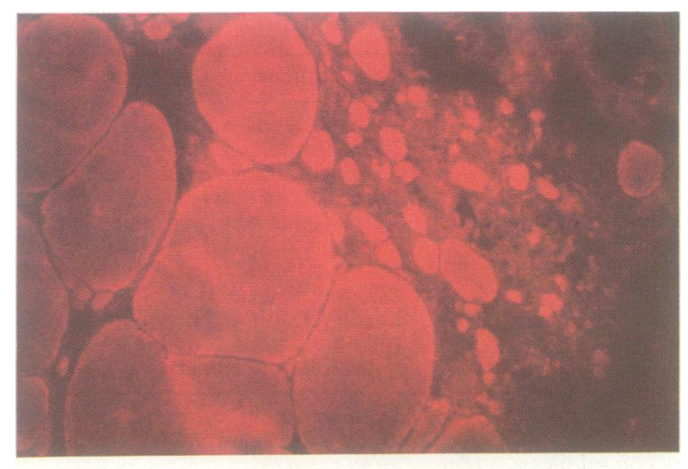

(a)

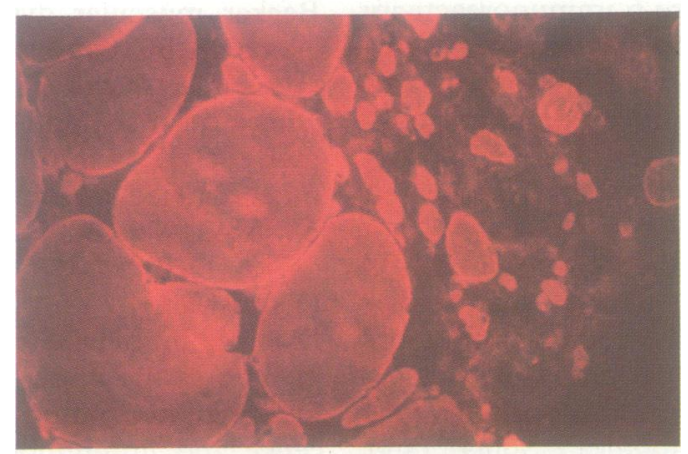

(b)

Figure 8 Serial sections of an intermediate patient (D/BMD 86). No immunoreactivity is detected with antibody D1-2 (8a, that was deliberately overexposed to make the muscle visible), while a weak labelling is visible with antibody DYS II (8b).

it for several months: almost invariably a reduction in staining intensity was detected in muscle of $B M D$ patients. We believe that staining reduction is probably a marker of increased in vitro dystrophin instability because: no reduction in staining was detectable in control muscle (and in muscle of patients with non-Xp21 dystrophies) after a similar period of time; moreover, spectrin another cytoskeletal protein, failed to show any staining reduction with time in the same patients.

We further used antibodies against muscle spectrin to check the integrity of the sarcolemma, ${ }^{15}$ and to demonstrate the specificity of dystrophin deficiency. In several patients with non-Xp21 disorders, the absence of dystrophin in fibres in an advanced state of necrosis was established, but the same fibres lacked surface immunolabelling with spectrin, indicating a complete loss of their plasma membrane.

Dystrophin analysis using immunocytochemistry was a relatively powerful and easy technique as an aid in diagnosing DMD. The application of the whole set of antibodies in DMD patients provided no further significant information compared with that of one antibody alone. It should be noted, however, that a negative immunostaining with only one antibody is not diagnostic of DMD, since the deletion of the cDNA region to which the antibody has been raised is a possibility, as already demonstrated ${ }^{16}$ and as shown in two of our cases. We believe that a negativity with a minimum of two antibodies (one $\mathrm{N}$-terminal and one C-terminal) should be obtained before a diagnosis of DMD is confirmed. In $20 \%$ of DMD cases that were analysed, a very weak immunostaining was observed only with antibodies raised against the $\mathrm{N}$-terminal region. This is not surprising as we (and other authors) have demonstrated that low levels of dystrophin mRNA are produced in the majority of patients with DMD. We propose that the mRNA produced is effectively translated into a protein up to the mutation/translocation region; the truncated protein is rapidly degraded, but in rare instances is still detectable with antibodies raised to the protein portion proximal to the mutation (our data, ${ }^{6-8} 19$; interestingly, this truncated protein, missing the C-terminal domain involved in linking dystrophin to a sarcolemmal glycoprotein $^{20}$ is correctly localised at the periphery of the membrane. The occurrence of scattered, positive fibres in the muscle of patients with DMD is a well-known phenomenon; ${ }^{6-8}$ we show that positivity is detectable with all antibodies used, indicating that a crossreactivity with the recently described dystrophinrelated protein ${ }^{22}$ is highly unlikely. The presence of scattered positive myotubes was also observed in a DMD foetus; the occurrence of this phenomenon in a myotube may explain the finding of groups of positive fibres later on in development. We also provide the first evidence for dystrophin positive fibres of a muscle spindle in a boy with DMD. No such positivity was found in our other patients with DMD, or in another patient described by Tanaka. ${ }^{23}$ Positivity was detectable in all fusal fibres and with all antibodies for a distance of $140 \mu$, but disappeared thereafter in all fibres. Again, the fact that this positivity was detected with antibodies directed towards different dystrophin domains and that it disappeared after many serial sections, demonstrates that positivity was unlikely to be due to crossreactivity with a dystrophin-related protein. The newly synthesised membrane of splitting fibres was also found to be positive (with all antibodies) in several boys with DMD, who did not produce dystrophin in the periphery of the same fibres.

A close correlation was found between quantity of dystrophin imm יnoreactivity and phenotype severity: mild BMD patients produced more dystrophin than severe BMD, and the latter presented more detectable dystrophin than intermediate patients; there were a few boys with DMD in whom some immunoreactivity was observed with $\mathrm{N}$-terminal antibodies and they had less dystrophin than intermediate individuals.

Of the individuals with deletions, two represented exceptions to the reading frame theory: ${ }^{24}$ one intermediate and one moderate BMD patient had frame-shift deletions instead of a translational in-frame mutation. In both of them a clear immunostaining was detected in all fibres with antibodies recognising portions of the protein distal to the deletion. One of the two patients (B/DMD 63), carried a deletion of exons 3-7; more than twenty individuals 
with the same deletion and an attenuated phenotype have been described. ${ }^{25-28}$ The finding that three minor additional in-frame transcript were detectable in the muscle of these subjects may explain their relatively mild phenotype. $^{28}$ The second patient, a 27 year old ambulant BMD, had an out of frame deletion involving exons $48-50$. The same mutation was associated with a severe DMD phenotype in a recent study. ${ }^{29}$ We do not know the reasons for this discrepancy: identical deletions producing a DMD and a BMD phenotype have already been reported. ${ }^{25}$ In some instances, however, it is not possible to come to a conclusion about the reading frame as exons might be only partially deleted. ${ }^{28} 30$

We conclude that the simultaneous use of several anti dystrophin antibodies is a powerful technique for detecting dystrophin abnormalities, including minor ones present in the muscle of patients with very mild phenotypes. Western blotting of muscle is useful especially when minor or no abnormalities can be detected with immunocytochemistry. However, the use of several antibodies greatly increases the likelihood of detecting some abnormalities with immunocytochemistry.

We thank the colleagues from the Paediatric and Paediatric peurology Clinics of Sardinia for referring their patients (in particular we thank Professor S De Virgiliis, Professor C
Mastropaolo and Dr G Serra). The financial support of Telethon-Italy to the project "Use of different strategies for the diagnosis of Duchenne and Becker carrier status" and of Regione Autonoma della Sardegna (11. 1980) is gratefully acknowledged.

1 Hoffman EP, Brown RH, Kunkel LM. Dystrophin: the protein product of the Duchenne muscular dystrophy locus. Cell 1987;51:919-28.

2 Koenig M, Monaco AP, Kunkel LM. The complete sequence of dystrophin predicts a rod-shaped cytoskeletal protein. Cell 1988;53:219-28.

3 Arahata $\mathrm{K}$, Ishiura $\mathrm{S}$, Ishiguro $\mathrm{T}$, et al. Immunostaining of skeletal and cardiac muscle surface membrane with skeletal and cardiac muscle surface membrane with antibody against Duchen

4 Zubrzycka-Gaarn EE, Bulman DE, Karpati G, et al. The Duchenne muscular dystrophy gene product is localised in sarcolemma of human skeletal muscle. Nature 1988;333:466-9.

5 Bonilla E, Samitt CE, Miranda AF, et al. Duchenne muscular dystrophy: deficiency of dystrophin at the muscular cell surface. Cell 1988:54:447-52.

6 Nicholson LVB, Davison K, Johnson MA, et al. Dystrophin in skeletal muscle II. Immunoreactivity in patients with

7 Shimizu T, Matsumura K, Hashimoto K, et al. A monoclonal antibody against a synthetic polypeptide fragment clonal antibody against a synthetic polypeptide frag

8 Nicholson LVB, Johnson MA, Gardner-Medwin D, Bhattacharya $S$, Harris JB. Heterogeneity of dystrophin expres-
sion in patients with Duchenne and Becker muscular sion in patients with Duchenne and Beck
dystrophy. Acta Neuropathol 1990;80:239-50.
9 Arahata K, Hoffman EP, Kunkel LM, et al. Dystrophin diagnosis: comparison of dystrophin abnormalities by diagnosis: comparison of dystrophin abnormalities by immunofluorescence and imn

10 Dubowitz V. Muscle Biopsy: a practical approach, 2nd ed. Eastbourne: Bailliere Tindall, 1985.

11 Chamberlain JS, Gibbs RA, Ranier JE, Nguyen PN, Caskey CT. Deletion screening of the Duchenne muscular dystrophy locus via multiplex DNA amplification. Nucl Acid Res 1988;16:11141-56.

12 Beggs AH, Koenig M, Boyce F, Kunkel LM. Detection of $98 \%$ of DMD/BMD gene deletions by polymerase chain reaction. Hum Genet 1990;86:45-8.

13 Koenig M, Hoffman EP, Bertelson CJ, Monaco AP, Feener C, Kunkel LM (1987). Complete cloning of the Duchenne muscular dystrophy (DMD) cDNA and preliminary genomic organisation of the DMD gene in normal and genomic organisation of the DMD gene
affected individuals. Cell 1989;50:509-17.

14 Hoffman EP, Fischbeck KH, Brown RH, et al. Characterisation of dystrophin in muscle biopsy specimens from patients with Duchenne's or Becker's muscular dystrophy. $N$ Engl f Med 1988;318:1363-8.

15 Clerk A, Rodillo E, Heckmatt JZ, Dubowitz V, Strong PN, Sewry CA. Characterisation of dystrophin in carriers of Duchenne muscular dystrophy. I Neurol Sci 1991;102:197-205.

16 Patel K, Leevers S, Abbs S, et al. Absence of dystrophin in Becker muscular dystrophy. Lancet 1989;I:47.

17 Oronzi Scott M, Sylvester JE, Heiman-Patterson T, et al. Duchenne muscular dystrophy gene expression in normal and diseased human muscle. Science 1988;239:1418-20.

18 Muntoni F, Strong PN. Transcription of the dystrophin gene in Duchenne muscular dystrophy muscle. FEBS Lett 1989;252:95-8.

19 Bulman DE, Murphy GE, Zubrzycka-Gaarn, Worton R, Ray PN. Differentiation of Duchenne and Becker muscular dystrophy phenotypes with amino- and carboxyterminal antisera specific for dystrophin. Am $\mathcal{f}$ Hum Genet 1991;48:295-304.

20 Campbell KP, Kahl SD. Association of dystrophin and an integral membrane glycoprotein. Nature 1989;338: 259-62.

21 Lowe DR, Hill DF, Dickson G, et al. An autosomal transcript in skeletal muscle with homology to dystrophin. Nature 1989;339:55-7.

22 Love DR, Morris GE, Ellis JM, et al. Tissue distribution of the dystrophin-related gene product and expression in the the dystrophin-related gene product and expression in the

23 Tanaka H, Mikiharu Y, Ishiguro T, Eguchi C, Nonaka I, Ozawa E. Expression of dystrophin on the cell surface membrane of intrafusal fibres of human skeletal muscle. Protoplasma 1989;152:109-11.

24 Monaco A, Bertelson C, Liechti-Gallati SHM, Kunkel LM. An explanation for the phenotypic differences between patients bearing partial deletions of the DMD locus. Genomics 1988;2:90-5.

25 Gilgenkrantz H, Chelly J, Lambert M, Rècan D, Barbot JC, Van Ommen GJB, Kaplan JC. Analysis of molecular deletions with CDNA probes in patients with Duchenne and Becker muscular dystrophies. Genomics 1989; 5:574-80.

26 Malhora SB, Hart $\mathrm{K}$ Klamut $\mathrm{HJ}$, et al. Frame-shift deletions in patients with Duchenne and Becker muscular deletions in patients with Duchenne

27 Chelly J, Gilgenkrantz H, Lambert M, et al. Effect of dystrophin gene deletions on mRNA levels and processing in Duchenne and Becker muscular dystrophies. Cell 1990;63:1239-48

28 Beggs A, Hoffman EP, Snyder JR, Arahata K, Specht L, Shapiro F, Angelini C, Sugita H, Kunkel LM. Exploring the molecular basis for variability among patients with Becker muscular dystrophy: dystrophin gene and protein studies. Am f Hum Genet 1991;49:54-67.

29 Roberts RG, Barby TFM, Manners E, Bobrow M, Bentley DR. Direct detection of dystrophin gene rearrangements by analysis of dystrophin mRNA in peripheral blood lymphocytes. Am $₹$ Hum Genet 1991;49:298-310.

30 Masafumi M, Masumura T, Nakajima T, Kitoh Y, Takumi T, Nisio H, Koga J, Nakamura H. A very small frameshifting deletion with exon 19 of the Duchenne muscular
dystrophy gene. Biochem Biophys Res Comm dystrophy gene. 